\title{
Vozes do nosso tempo: um texto, um caminho: J. Munguambe \& H. Joshua
}

\author{
Voices of our time: a text, a path: J. Munguambe \& H. Joshua
}

DiONÍSIO BAHULE (iDa

\begin{abstract}
Proposição I «Quer se trate da irregularidade de Baudelaire, da surpresa de Apollinaire, do assombro de Perse, em todos os casos é um desligar de um certo olhar, de uma certa resignação temporal, de um certo enclausuramento do ser que a poesia propõe.»

J. BURGOS, Pour un poétique de I' immaginaire. Paris. 1982.
\end{abstract}

Proposição II «O que quero dizer com o poeta-em-um-poeta é aquilo que, mesmo no maior dos poemas - Rei Lear ou Paraíso perdido - é a própria poesia e não outra coisa. [...] 0 poeta-em-um-poeta seculariza o sagrado, fazendo com que busquemos análogos explicativos.» (BLOOM, 2013)

\section{Resumo}

Qu'Est-ce qu'un Auteur?, é uma proposta interrogativa formulada por Foucault logo depois de Barthes declarar em 68 La Mort de I'Auteur como negação forçada à intenção semiótica do verbo acabado isto é, descorolar o modo simbólico de percepcionar a arte por meio de novas propostas poéticas que, não só questionam o edifício estético já estabelecido como também propõem por meio de uma assinalada dose de negação e integração do léxico marginalizado. Diferentemente de um fazer artístico preso na nostalgia de um lugar-comum; da busca por meio de rompimento com uma literatura de carácter panfletário-partidário dado pela Charrua dos anos 80 como signo de um fazer com rotulagem tipicamente moçambicana - a geração que configura a estética Pós-2000 - a que também a chamo por geração da náusea - rompe com esta linha de um fazer subjacente à carruagem de

a Universidade Pedagógica de Moçambique, Maputo, Moçambique. Mestrando em Ensino de Português, e-mail: dionisiobahule@gmail.com 
reparação colonial para significar o acto de ser por meio de uma estética de contrariedades coroado pela insatisfação do um país.

Palavras-Chave: Estética Pós-2000. Poesia. Hirondina Joshua. Jaime Munguambe.

\begin{abstract}
Qu'Est-ce gu'un Auteur?, is an interrogative suggestion worded by Foucault thereafter Barthes had declared in $68 \mathrm{La}$ Mort de I'Auteur as a forced negation to semiotic intention of a terminated verb, that is, to wash down the symbolic way of perceiving the art by means of the recent poetic proposals that, not only question the aesthetics building already established as well they suggest by means of a marked dose of negation and incorporation of marginalized lexicon. Far from an artistic exercise bound on longing of a commonplace; of a search by means of split with a literature of pamphleteer-partisan supplied by Charrua in eighty decade of the last century as a sign of an artistic exercise with a labeling typically Mozambican - the generation that configures the post-2000 aesthetics - the one that I also name as generation of nausea - splits with this line of an artistic exercise subjacent to the carriage of colonial expiation to mean the act of being by means of an aesthetics of contrariness crowned by dissatisfaction of a country.
\end{abstract}

Key-Words: Post-2000 Aesthetics. Poetry. Hirondina Joshua. Jaime Munguambe.

Aliás: um dia - em pleno tempo de conturbadas modificações como as já havidas em nome da geração oásis em 97 — na AEMO — (Associação de Escritores Moçambicannos) — Sartre — em resposta ao pedido de Jacques Calmy e Marc Beigbeder — virou para a multidão que se encontrava no Club Maintenant em París para dizer aquilo que se traduzira em manifesto de ruptura e condução para a febre do pós-guerra segunda: «a existência precede a essência». E o que será isso de existência preceder a essência para o exercício de amadurecimento criativo? Essa categoria interrogativa de procurar a proveniência do segundo saindo da instância primeira? E a essência — este estágio depois de compreender a subjectividade? Uma vez li em Heidegger — na sua « $A$ Origem da Obra de Arte» — um breve, mas condensado livro. Nele há um conceito utilizável, o de origem como «aquilo a partir do qual e através do qual uma coisa é o que é, e como é», (HEIDEGGER, 1977, p. 11). E a essa coisa que é, e como é - a instância segunda que se chega a ela pelo cogito cartesiano, mas pelo depois de fruir a subjectividade; a concretude; o lugar do domicílio; essa temporalidade da demora. E 
preceder a essência é, antes dela, se instalar no concreto — nessa coisa a que chamo de recolbimento. O acto de demorar no domicílio. É isso que me parece acreditar ser impossível pensar a poesia fora do seu carácter concrecto como um equivalente ao sensível que restaura o vivido à superfície.

Desde o Íon há essa pista; do concrecto jogado ao poema. Num exercício incestuoso - podemos forçar a ideia do manifesto estético — olhando a perspectiva de Bloom que, o levando a construir o conceito de poeta-em-um-poeta como categoria de impermeabilidade ideológica — remodela-se continuamente no complexo jogo «entre a enunciação metafórica e a transgressão regrada das significações usuais de nossas palavras» (RICOEUR, 2019, p. 3). Este é um polo. O outro, o que fez de Aristóteles a paixão de muitos e, talvez, a incivilidade de historiadores, é ter pensado a poesia como «algo de mais filosófico e mais sério do que a história»; a ideia do universal só é possível enquanto pensada na poesia como atmosfera da reinvenção e utopia e, na História - o particular - porque a ela reserva-se-lhe o exercício de «mostrar como uma coisa levou a outra; [...] como algo veio a acontecer, ligando a situação inicial, o desenvolvimento e o resultado de um modo que faz sentido» (CULLER, 1999, p. 27). Ao poeta é expressamente proibido pedir-se-lhe a narração do que foi, mas podemos, nós como humanos, pedi-lo que nos faça sonhar continuamente, isto é: dar-nos a coragem de aceder a metáfora da navigatio vitae; aquilo que abrindo o sujeito ao desconhecido traduz-se no paradigma de Ulisses ${ }^{1}$.

Ora, não será esta abertura à totalidade do ser, ao assombro — esse «momento inicial» que indica o estar profundo do homem que torna Platão irritado relativamente à poesia? Ou: não terá sido por aquilo que, mais tarde, Nietzsche fez gravitar ao contrapor Apolo [o deus da perfeição e do homem] e Dionísio [o deus da embriaguez e da vontade de poder]? Acho ser esta, a segunda opção, que fez Platão no livro X da República afirmar que: «A cidade cujo princípio acabamos de estabelecer é a melhor, sobretudo em virtude das medidas tomadas contra a poesia» (BADIOU, 2002, p. 29). Para conceber o colectivo

1 «Herói que muito viajou e muito sofreu e que, justamente por isso, é capaz de orientar a sua perigosa rota através de todos obstáculos divinos e humanos que se lhe interpõem» (BODEI, 1997). 
em termos cognitivos, Platão pede que a poesia ${ }^{2}$ seja aniquilada; expulsa para fora da humanidade — da casa — lugar que congrega, porque ela é a «ruína» dos que a «ela» dedicam a sua atenção; a escutam e se deixam penetrar — catharsis — deposição da alma e das paixões. O pretexto é mesmo esse: querer instituir uma república onde o poema como metáfora de negação ao «logos calculador» seja oferenda para o esquartejamento. Afinal de contas: «os poetas nada sabem». Mas dizer que eles não participam da episteme enquanto lugar da concretização do racional é forçar demais. É querer inclusive dizer que eles são fabricadores de simulacros.

A formulação do cânone literário das Literaturas Africanas tiveram como território de acção epistemológica no poema; é e foi aqui onde o arranjo do grito colectivo começou, na tradução do vivido; do drama colectivo deslocado para variados recursos estéticos. Mostram-se aqui as propostas binárias dadas por Kwame Appiah. Para isto, ele tem toda e qualquer outra razão ao questionar dentro dos dualismos: sinceridade como articulação de si-plural para dentro de um específico lugar e, principalmente, quando este certo lugar específico teve o drama de pilhagem antropológica e, do autêntico - como esse outro caminho do artista como rosto que vive dentro de uma meada à margem; uma categórica ilusão de se pensar o si para si nesse insolúvel delírio de criar contusões. Agrada-me encontrar em Ferreira Gullar a mesma interrogativa. Quase nos mesmos moldes, deslocando-se obviamente para a ideia de autonomia da arte em contexto de nações em subdesenvolvimento «na medida em que não permite reconhecer sua condicionalidade social» — embora seja isso uma pura fantasia de arranjo de terminologias. Ambos forçam a pensar a arte dentro de um contexto-outro. $\mathrm{O}$ de reformulação do eu. Dessa «loucura da sinceridade» que Meursault — esse homem que cede ao impulso dos dedos no revólver — se contorce para concretizar a incógnita do homem e do seu tempo. Adorno também, que tinha razão ao proibir o poema depois de Auschwitz. Como seria? Pensar o humano depois de fraturá-lo? Empurrá-lo a essa jurisdição que desafia até hoje o cálculo? Óbvio. Tinha percebido. A totalidade do

2 «Antes de se fundar no conteúdo imoral das fábulas, a proscrição platónica dos poetas funda-se na impossibilidade de se fazer duas coisas ao mesmo tempo. A questão da ficção é, antes de tudo, uma questão de distribuição dos lugares» (RANCIÈRE, 2018). 
racionalismo de Leibniz que repousa naquela sua famosa frase; do tudo parecer explicável e calculável — era inoperante para o poema — para este grau das coisas que reside «onde a ponte entre uma causa e um efeito se quebra». Parece ser aqui possível recordar a pergunta de Laurence Sterne sobre a moradia do poema. Um dia, Kundera também voltou-se para esta questão de Sterne por perceber que este acto vulnerável, esta angústia, esta penúria, está na digressão, no incalculável do outro lado da casualidade. O New Negro Movement por exemplo é expressão acertada disto que Gullar e Appiah procuram. Mas, temo ser isso ainda uma verdade - acho que Platão não tinha acesso ao significado da Metáfora. Badiou, nisso parece ter razão: «Platão não consegue sustentar essa máxima até o final, essa máxima que promove o matema e bane o poema» (BADIOU, 2002, p. 33).

Ora, sendo a poesia, como toda arte, o lugar da mimesis fantástica, ela nega o que se pode chamar de representação ontológica, no sentido de identificação. É aqui onde para Platão, o «princípio político» nasce pela total «exclusão do poema» ${ }^{3}$. Mas o que será a politeia senão o colectivo; a casa; a humanidade do homem? Ou: o que será a politeia senão a centralidade da subjectividade humana — poesia? É admissível pensar a poesia como lugar da linguagem — «recinto, isto é: a casa do ser». Pensar desta maneira é admitir que o poeta «é o que se encontra mais perto da habitação do ser». É na casa onde a invocação ao âmbito mais profundo acontece, o ser, onde o Topos, pedindo o termo a Aristóteles, realiza-se. Este lugar-comum, que nos pode levar a renovação da Lógica Jurídica de Perelman, mostra a transposição de um cogito cartesiano para uma pragmática de valores que anula o estático da dimensão lógico-formal que Platão pede para a poesia — a dianoia — «o labor do logos calculador ${ }^{4} »$. A té aqui Merleau-Ponty tinha razão ao fatigar o cogito para o homem começar pela sua necessidade de se instalar no concreto para invocar a percepção; é na contingência; no estar e na fruição que se elabora toda a arte como um voltar-se para as coisas-elas — esse espaço de forja e da verdade.

3 «Ou pelo menos daquilo que Platão chama a dimensão imitativa do poético. O destino da política verdadeira repousa sobre a firmeza da atitude com relação ao poema» (BADIOU, 2002, p. 29).

${ }^{4}$ Cf. HENRIQUES, 2013. 
Este é o agrado que tenho em pensar «Os Ângulos da Casa» como possibilidade de ida e de busca; aliás: como simplesmente caminhos variados que nos abrem a possibilidade de caminhar ao nosso domicílio — casa; ao lugar-primeiro de permanência - nosso habitat. Olhando para os textos da Hirondina Joshua há uma rápida denúncia que fica a espreita — aquele contexto filosófico-literário que o chamo de poetologia existencial; encontra os seus movimentos na existência de duas abordagens possíveis: [I]: na negação de todo e qualquer estágio de metafísica; está na estrada de quem diz — o que não passa por um estágio de mensurabilidade nada diz. Quem aí está para senti-la? Pergunta renovando, por outro lado, toda uma tradição que nos remete à ideia da visão e da temporalidade. Faz-nos voltar a Orfeu, que matou a sua Eurídice pelo olhar; Psique que se perde ao ver Eros; Narciso, que morre ao contemplar a sua própria imagem numa mistura de negação do incalculável e a crítica ao logocentrismo cartesiano.

[...] os móveis desarrumados tornam-se Imóveis/diante dos olhos e suas veias/na estante, o tempo rói o dorso do osso (JOSHUA, 2016, p. 13).

Nestes três versos, H. Joshua leva-nos a requalificar a mitologia do olhar, ao dar à janela um grau de acesso à mundividência pelos olhos; a dar créditos àquilo que celebra a cultura visual que, encontrando o seu ponto de viragem no Pós-Segunda Guerra, alcança a sua realização na imagética da comunicação principalmente depois de Maio de 1968, na França, quando o teatro encontra a sua nova fundamentação para desocultar por meio do corpo e do grito o outro passivo no tradicional modelo dramatológico ${ }^{5}$. Mas também traduz uma constante temporal: «na estante, o tempo rói o dorso do osso», (JOSHUA, 2016, p. 13) Entra aqui o segundo ponto do que chamo de Poetologia Existencial ao grande exercício dos escritores do Pós 2000 ou àqueles que abrem o novo século.

O segundo movimento aparece quando a: [II]: existência na experiência — actual ou possível — por oposição a uma constante indefinição própria do Da-sein, enquanto projecto, cria no sujeito poético uma visão dramática da condição humana - o vazio como «O Grito» de Munchi, a «Mulher em Pranto» de Picasso e «A PIDE» de Alberto Chissano revelam. O homem que se torna pelo tempo e pela circunstância. Os «móveis

${ }^{5}$ Cf. RYNGAERT, 1998.

Rev. Filos., Aurora, Curitiba, v. 33, n. 59, p. 499-509, mai./ago. 2021 
desarrumados» traduzem na velha fórmula da metáfora — o deslocamento e, consequentemente, a substituição — revelando o estado interior da voz poética; como também, da revelação do momento.

A terrena condição, fusão da química e física ou electrões e a/gravidade. Bem se vê: a verdadeira gravidade é a porta que canta/com tons graves a aguda substância da existência./E quem aí esta para ouvi-la? (JOSHUA, 2016, p. 13).

Quem aí está para senti-la?/Os dedos se foram, a cabeça se foi,/toda biologia se foi./Toda ciência se foi. Resta a «aicnêic», cá/por mim o inverso vale, se é que a isto podemos chamar de:/conhecimento sistemático; pondo a coisa motora da metafísica abaixo (JOSHUA, 2016, p. 13).

Quer seja a negação da metafísica — «pondo a coisa motora da metafísica abaixo», quer a crítica sem alma dos avanços da ciência, juntam-se a um certo absurdo que vem do Dadaísmo e de um Estado Moçambicano hostil ao humano; é como se a H. Joshua pedisse uma resposta a Carl Sagan, Stephen Gould ou Vitaly Goldanski sobre a essência da ciência. As questões que atravessam «Os Ângulos da Casa» surgem como que para acordarmos para nossa casa; ao nosso lugar de permanência. É o que continuo pensando ao traduzir casa por interioridade. Quando os nativos de Inhambane se dirigiram, amavelmente, à Vasco Da Gama e aos seus acompanhantes dizendo: Bela Nyumbane ou, os Índios — estavam a dizer: aqui está o que somos; o nosso ser.

O exercício da H. Joshua desce cada vez mais ao lugar do assombro; ao espaço manifestante do ser, ao céu procurado por Freud e que o Surrealismo subsequente retrabalha e com ele ganha um estatuto de grandeza. Ao recorrer continuamente ao quarto, diz, na surdina, que a frequência do mundo actual está assaltada. Figuras como quarto desarrumado; gavetas postas ao tecto; janelas ao chão e roupa estendida no coração abrem-nos ao segredo do que somos - desorientados. «Vivemos no efémero, na obsolescência acelerada, no capricho subjectivo, como se os valores mais sagrados, perdidas as bases, pudessem entrar no grande mercado dos valores mobiliários e flutuar por seu turno»6. Ora, se para Nietzsche a «Morte de Deus» significa a morte de Homem, qual será o significado para a H. Joshua? Se para Heidegger o niilismo é igual ao

${ }^{6}$ Cf. DINDÉ, 2004.

Rev. Filos., Aurora, Curitiba, v. 33, n. 59, p. 499-509, mai./ago. 2021 
esquecimento do Ser que se transforma em valor de troca — «Os Ângulos da Casa», ao nos levarem à interioridade, estarão num exercício de volta para casa? Porém, acredito encontrar neste texto o primeiro elemento que liga J. Munguambe a H. Joshua. O fascínio pelo tempo.

As escadas deslocam-se para onde o Sol dorme./Atravessam as idades vivas das coisas./Esquecem-se do meio./Matéria orgânica./Para cima e para baixo deslocam corpos do silêncio, apoiando-se/nas lâmpadas e nas grandes campainhas da loucura (JOSHUA, 2019, p. 15).

A imagem vai e volta. Solta a brancura da cura do outro lado./Inclinado um pouco, inclinado o dorso: fala comigo a/voz dos olhos do mundo (JOSHUA, 2019, p. 15).

O tempo liga os dois por meio das idades, mas Munguambe distancia-se de Joshua ao explorar o lado mais escuro; o abismo; o ilógico; o jogo das imagens; combina múltiplas variantes para construir um sentido. Chamo-o de Poeta do Ilógico. Faz incestos com palavras; brinca com o corpo, talvez a sua maior obsessão. Se em H. Joshua temos «casa» como ritual de criação, J. Munguambe oferece-nos o corpo como a sua catedral de imaginação. As vanguardas Europeias encontram vida no edifício poético de J. Munguambe, principalmente o Dadaísmo e o Surrealismo. Do primeiro busca a atitude do irracional; do ilógico e do ilegal. Tudo à margem das convenções. Foi assim que aparecia o Dadaísmo para repudiar «o que consideram ser as causas do conflito [I. G. Mundial], nomeadamente o sistema e a sua dependência excessiva da razão, da lógica, das regras e dos regulamentos» (GOMPERTZ, 2014). Com este movimento, J. Munguambe brinca à semelhança do que os Futuristas faziam na influência do Design Gráfico - com nomes como Mallarmé [Un coup de dês], Tommaso Marinetti, Fortunato Depero, que sintetiza a ideia de sobreposição de imagens.

No tempo é onde começa: a ideia que ele apresenta como parte que compõe o seu título — AS ID ADES, ou simplesmente: IDADES. Certamente pode-se questionar: o que nos poderia dizer este lexema - idades. Ou, que elementos substanciais podem nos levar a afirmar que $A S I D A D E S$ são parte de um pensamento que vasculha o existencial? Em resposta, poderia colocar de forma interrogativa algo mais ou menos como: que idades se podem fazer fora do tempo? Entendamos todo o tempo como horizonte que compõe 
transitivamente qualquer ser, enquanto um filamento subsistente. Quer seja este um ente do ser ou simplesmente um ente enquanto ente.

É aqui onde procuro imaginar Jaime Munguambe como alguém que nasce do existencialismo, estruma-se no metafísico, cresce no imagismo que, tendo expoentes como Ezra Pound e Amy Lowell, advoga «uma apresentação clara e altamente visual», para, com maturidade, desaguar no surrealismo, onde colhe novamente a ideia de choque; do ilógico; do jogo de imagens e palavras. Aqui, ele trava conversas com André Breton; sente-se fascinado para o mundo onírico apresentado por Salvador Dali com a sua combinação de imagens e, no fim, define-se como poeta do ilógico. Ilógico - enquanto aquele que gosta de manter relações incestuosas com a palavra para apresentar um convite ao leitor como aquele que reconfigura novos sentidos ao panorama interpretativo. A ideia de inter-lugares apresentada por Homi Bhabha parece ganhar subsídios neste outro mundo iniciado pelo Teatro Pós-Dramático.

Outro elemento interessante é o DO VENTO. Este, completa o título todo que apresenta o livro. Aliás, se H. Joshua joga abaixo a metafísica, J. Munguambe socorre-se dela para levar o seu voo. A tradição manda dizer que esta palavra surge para dar consolo ao âmbito angustiante da pergunta sobre o ser — ou seja: a última razão possível. O vento metamorfoseia-se como o inominável; a coisa transcendental; o possível momento da respiração; da questão que se coloca no centro de toda arte digna deste nome — a questão antropológica. Idades que se fazem no tempo — comportam a ideia do ser que se torna; e o vento, a maneira simbólica de transladar o ser, essa «criança ao colo da noite», como atesta o texto [Os Intervalos dos Nós].

O suor desce/sobre a tontura das águas/e um barco geme na noite./Os braços da sintaxe/dissecam nos segredos das luzes/a solidão é apenas uma criança/ao colo da noite.

Há uma rebuscada atribuição e valorização da metáfora como um recurso de «inovação semântica»; como o que Ricoeur procura dentro da linguagem poética em uma nova nomenclatura - a referência metafórica para «expressar esse poder do enunciado metafórico de reescrever uma realidade inacessível à descrição directa». E este barco que geme na noite - a mulher que traduzida e desvelada dentro d'um elemento cuja navegação 
remete-nos ao acesso da interioridade humana. Mas pode ser também uma ideia talhada do Velho e o Mar de Ernest Hemigway. «Oitenta e quatro dias sem peixe nenhum. Oitenta e quatro dias de vazio; de derrotas; de frustração». Numa leitura rápida, como será que o pescador nos parece? Neste breve poema em prosa, o velho faz-nos perceber o jogo épico que, nos remetendo para a vida como um jogo de acontecimentos faz ganhar a heroicidade como conjugação de argolas que caracterizam o fluxo épico.

Mas não será também o barco que geme na noite uma disfarçada maneira de contar os «estames altos; os gestos lentos; as carnes e as águas» no cerrado aperto de dois corpos dissecados no segredo das luzes? Não será o barco esse corpo de mulher que geme na fornicação? Este exercício de deslocação e substituição que a metáfora nos empresta, leva-me à Jaime Munguambe como caminho para chegar a Eduardo White. Imaginemos o seguinte texto de White, precisamente na última estrofe. Gosto da flor que és/assim exposta/por entre os dentes/e a búmida língua da volúpia. Há neles uma disfarçada grandeza de celebrar o âmbito feminino. Flor exposta por entre os dentes; húmida língua da volúpia ou, o suor que desce sobre a tontura das águas... os braços da sintaxe... o que nos seria a linguagem senão os sentidos em devir?

\section{Referências}

BADIOU, A. Pequeno Manual de Inestética. São Paulo: Liberdade, 2002.

BLOOM, H. A Anatomia da Influência - Literatura como Modo de Vida. Rio de Janeiro: Objetiva, 2013.

BODEI, R. A Filosofia do Século XX. 35ª ed. Lisboa: Edições 70, 1997.

CULLER, J. Teoria Literária - Uma Introdução. São Paulo: Beca Produções Culturais, 1999.

DINDÉ, J Para Onde Vão os Valores? Lisboa: Ed. Instituto Piaget, 2004.

JOSHUA, H. Os Angulos da Casa. Maputo: Fundação Fernando Leite Couto, 2016.

HEIDEGGER, M. A Origem da Obra de Arte. Lisboa: Edições 70, 1977.

HENRIQUES, A. Argumentação e Discurso Jurídico. 2. ed. São Paulo: Atlas, 2013.

GOMPERTZ, W. 150 Anos de Arte Moderna Num Piscar de Olhos. Lisboa: Bizâncio, 2014.

MUNGUAMBE, J. As Idades do Vento. Maputo: Fundação Fernando Leite Couto, 2016. 
RANCIÈRE, J. A Partilha do Sensivel-Estética e Política. São Paulo: Editora 34, 2018.

RICOEUR, P. Tempo e Narrativa 1 - A intriga e a narrativa histórica. São Paulo: Martins Fontes, 2019.

RYNGAERT, J.-P. Ler o Teatro Contemporâneo. São Paulo: Martins Fontes, 1998.

VOLOCHÍNOV, V. N. A Construção da Enunciação e Outros Ensaios. São Paulo: Pedro e João, 2013.

RECEBIDO: $13 / 04 / 2021$

RECETVED: 04/13/2021

APROVADO: $10 / 07 / 2021$

APPROVED: 07/10/2021 